\title{
REVISÃO DO GÊNERO NEOCALVIA CROTCH \\ (COLEOPTERA, COCCINELLIDAE) ${ }^{1}$
}

\author{
Carla de Lima Bicho ${ }^{2}$ \\ Lúcia Massutti de Almeida ${ }^{2}$
}

\begin{abstract}
Revision of the genus Neocalvia Crotch (Coleoptera, CoccinelliDAE). The genus Neocalvia Crotch, 1871 is revised through the study of external morphology and especially of the genitalia characters. A key to the species is added. Neocalvia areolata Gorham, 1892 was not studied and the original description is transcribed.

KEY WORDS. Coleoptera, Coccinellidae, Coccinellinae, Neocalvia, revision
\end{abstract}

O gênero Neocalvia Crotch, 1871, é formado por oito espécies, que se distribuem do norte da América Central ao sul da América do Sul.

Os principais estudos taxonômicos realizados no gênero foram os de MULSANT (1850) e CROTCH (1874). CAMARGO (1937), estudou quatro espécies, incluindo uma chave para identificação baseada nos caracteres da genitália masculina, além de tratar de aspectos biológicos, principalmente de $N$. anastomozans Crotch, 1874, predadora de larvas e adultos de diversas espécies de Psyllobora Chevrolat, 1837 (Coleoptera, Coccinellidae).

Este trabalho tem como objetivo realizar a revisão taxonômica do grupo, através de estudo detalhado dos caracteres morfológicos, com especial atenção aos da genitália masculina e feminina.

\section{MATERIAL E MÉTODOS}

O material utilizado foi emprestado pelas seguintes instituições: (BMNH) The Natural History Museum, Londres, Inglaterra; (DZUC) Department of Zoology, University of Cambridge, Cambridge, Inglaterra; (DZUP) Coleção de Entomologia Pe. J.S. Moure, Departamento de Zoologia, Universidade Federal do Paraná, Curitiba, Paraná, Brasil; (MAPA) Museu Anchieta, Porto Alegre, Rio Grande do Sul, Brasil; (MCIC) Museu do Capão da Imbuia, Curitiba, Paraná, Brasil; (MNHN) Muséum National d'Histoire Naturelle, Paris, França; (MNRJ) Museu Nacional, Universidade Federal do Rio de Janeiro, Rio de Janeiro, Brasil; (MZSP) Museu de Zoologia, Universidade de São Paulo, São Paulo, Brasil; (PUCE) Pontifícia Universidade Católica do Equador, Quito, Equador; (ZMHU) Zoologisches Museum

1) Contribuição número 1012 do Departamento de Zoologia, Universidade Federal do Paraná.

2) Departamento de Zoologia, Universidade Federal do Paraná. Caixa Postal 19020, 81531-990 Curitiba, Paraná, Brasil. 
der Humboldt Universitaet, Berlim, Alemanha. A sigla PROFAUPAR, utilizada no material examinado, refere-se ao Projeto Levantamento da Fauna do Estado do Paraná, realizado pelo Departamento de Zoologia da Universidade Federal do Paraná.

Para o estudo morfológico os exemplares foram fervidos, em água e sabão, e dissecados. Estruturas pequenas, como peças bucais e genitália, foram colocadas em solução de hidróxido de potássio $(\mathrm{KOH})$ a $10 \%$ e novamente aquecidas, por alguns minutos, para a remoção de restos de tecidos.

O reconhecimento das estruturas e os desenhos foram feitos em microscópio estereoscópico e microscópio óptico, ambos com câmara clara. Para fixação das peças na posição desejada, usou-se gelatina glicerinada. Algumas figuras foram feitas de lâminas já preparadas da ex-coleção Felisberto Camargo (MNRJ).

A terminologia adotada seguiu GORDON (1985) e a interpretação da venação alar, MARINONI \& ALMEIDA (1983).

\section{Neocalvia Crotch, 1871}

Neocalvia Crotch, 1871: 4 (criação do gênero, lista); 1874: 129-130 (descrição e diagnose espécies). Burmeister in Berg, 1874: 289 (descrição espécie). - Harold, 1875: 188 (comentário). - Chapuis, 1876: 183 (sistemática). - Gemminger \& Harold, 1876: 3756-3759 (catálogo). - Gorham, 1892: 169 (descrição e diagnose espécie). - Weise, 1904a: 194, 195 (descrição espécie, citação). - 1904b: 357 (comentário). - Bruch, 1915: 387 (catálogo). - Korschefsky, 1932: 530 (catálogo). - Lima, 1937: 12 (descrição espécie). - Camargo, 1937: 361-377 (biologia, sistemática, chave espécies). - Blackwelder, 1945: 454 (catálogo). - Marinoni \& Almeida, 1983: 268-270,273 (morfologia). Arioli, 1985: 27-29 (chave espécies). - Gordon, 1987: 15 (catálogo). - Vanderberg \& Gordon, 1988: 33-35 (sistemática). - Fürsch, 1990: 7-18 (catálogo).

Espécie-tipo: Coccinella cayennensis Gmelin, 1790; designada por Crotch, 1874.

\section{Histórico}

FABRICIUS (1787) descreveu a primeira espécie de Neocalvia, Coccinella duodecimguttata.

GMELIN (1790) renomeou Coccinella duodecimguttata como C. cayennensis, pois Fabricius havia usado um nome pré-ocupado (PODA 1761).

OLIVIER (1791) também renomeou a espécie de Fabricius como Coccinella connata.

MUlSANT (1850) descreveu as espécies Calvia blanchardi e C. fulgurata e, em 1866-67, fez a diagnose dessas espécies e de C. cajennensis (uso incorreto do nome dado por Gmelin).

CROTCH (1871) em lista dos Coccinellidae, citou as espécies N. blanchardi, $N$. cayennensis, $N$. anastomozans e $N$. fulgurata. Em 1874, descreveu o gênero Neocalvia, designando como espécie-tipo Coccinella cayennensis Gmelin, 1790. Descreveu também, as espécies $N$. anastomozans, $N$. guerinii Crotch, 1874 e $N$. mniszechii; redescreveu brevemente as espécies $N$. duodecimguttata e $N$. fulgurata e citou $N$. blanchardi. Portanto, Crotch, mesmo utilizando o nome correto para a espécie-tipo, ao fazer a redescrição desta espécie, voltou a utilizar o nome duodecimguttata, sinonimizando cayennensis.

BURMEISTER in BERG (1874) descreveu Calvia dentatofasciata. 
CHAPUIS (1876) redescreveu Calvia como subgênero de Halyzia e no catálogo de GEMMINGER \& HAROLD (1876) foram listadas as espécies: H. anastomozans, $H$. blanchardi, $H$. cayennensis, $H$. dentatofasciata e $H$. fulgurata.

GORHAM (1892) descreveu e ilustrou Neocalvia areolata e redescreveu $N$. duodecimguttata, voltando a utilizar este nome, tendo $N$. cayennensis como sinônimo.

WEISE (1904a) descreveu, brevemente, Neocalvia bruchi e comparou-a com N. guerinii e $N$. anastomozans.

WEISE (1904b) comentou que na página 169 do trabalho de Gorham, o nome N. duodecimguttata (Fabricius, 1787) é outra vez introduzido, embora o mesmo já tivesse sido considerado "nomen nudum", corretamente, por Gmelin, em razão da espécie ser homônimo (PODA 1761).

BRUCH (1915) listou Halyzia dentatofasciata (Berg) e Neocalvia bruchi Weise como sinônimos de $N$. dentatofasciata.

No catálogo de KoRSCHEFSKY (1932) foram relacionadas as seguintes espécies: $N$. anastomozans, $N$. areolata, $N$. blanchardi, $N$. bruchi, $N$. dentatofasciata, $N$. guerinii, $N$. duodecimguttata, N. fulgurata e N. mniszechii, mencionando, erroneamente, Coccinella duodecimguttata como espécie-tipo.

Lima (1937) descreveu Psyllobora grandis que, foi sinonimizada com $N$. anastomozans, por Camargo, no mesmo ano.

CAMARgo (1937) em trabalho sobre notas taxonômicas e biológicas de $N$. anastomozans, $N$. cayennensis, $N$. dentatofasciata e $N$. fulgurata, apresentou comentários sobre $N$. areolata e chave para identificação baseada em caracteres da genitália.

BLACKWELDER (1945) relacionou as espécies: N. anastomozans, $N$. areolata, $N$. blanchardi, $N$. cayennensis, $N$. dentatofasciata (citada erroneamente como $N$. dentofasciata), N. fulgurata, N. guerinii e N. mniszechii.

MARINONI \& ALMEIDA (1983) utilizaram asa de Neocalvia anastomozans, em estudo comparado da venação alar de Cerambycidae e Coccinellidae.

ARIOLI (1985) apresentou uma chave para identificar os Coccinellini que ocorrem no Rio Grande do Sul, incluindo as espécies $N$. anastomozans e $N$. fulgurata, onde utilizou os seguintes caracteres: margem anterior do mesosterno, linha pós-coxal, cor e forma das máculas do pronoto e élitros.

GORDON (1987), em seu catálogo do material existente na Coleção Crotch, relacionou as espécies $N$. duodecimguttata, $N$. fulgurata, $N$. guerinii, $N$. anastomozans e $N$. mniszechii. Nesse trabalho fez referência ao holótipo das espécies $N$. guerinii e $N$. anastomozans e designou lectótipo para a espécie $N$. fulgurata.

VANDERBERG \& GORDON (1988) estudaram o relacionamento filogenético dentro do gênero Erythroneda Timberlake, 1943 usando Neocalvia como grupo externo. Esses autores sustentaram a monofilia dos gêneros baseada numa série de caracteres derivados.

FÜRSCH (1990) em lista dos gêneros e subgêneros válidos de Coccinellidae para o mundo, citou Neocalvia com a respectiva espécie-tipo: Coccinella cayennensis Gmelin, 1790 (=Coccinella duodecimguttata Fabricius, 1787). 
Diagnose. Corpo ovalar a arredondado, robusto, convexo, glabro, tegumento com pontuações fracas e esparsas, amarelado a marrom e com máculas marrons a amarelas. Superfície ventral amarelada a marrom.

Cabeça profundamente encaixada no protórax. Olhos grossamente facetados. Gena estendendo-se abaixo dos olhos (Fig. 1). Antenas longas, com poucas cerdas, onze artículos, todos mais longos que largos, sendo os três últimos mais dilatados (Fig. 2); o comprimento total alcança os dois terços da margem lateral do pronoto. Clípeo com ângulo ântero-lateral projetado, unido à fronte e sem linha de sutura. Labro tranversal, convexo, pubescente, com borda arredondada (Fig. 3). Mandíbulas robustas, com ápice bífido; mola com dente; prosteca com comprimento, aproximadamente, igual a quatro vezes a largura e com cerdas na borda externa (Fig. 4). Maxilas com o último artículo do palpo distintamente securiforme (Fig. 5). Lábio com borda apical larga e truncada; palpos labiais com o segundo e o terceiro artículos mais longos que largos (Fig. 6).

Pronoto com a borda anterior escavada em volta da cabeça. Processo prosternal arredondado. Élitros ovalados, com calo umeral pouco saliente e margem lateral esplanada. Epipleura larga e plana, sem escavações para a recepção dos fêmures. Asas membranosas com a ligação apical da Subcosta e Rádio unida ao Setor por forte curvatura; base do Cúbito fortemente curva; extremidade apical da Empusal nítida e com grau de inclinação em relação à Média Posterior mais Cúbito aproximadamente de 45 graus (Fig. 7). Tíbias anteriores livres de espinhos, médias e posteriores (Fig. 8), cada uma, com dois espinhos na porção apical. Garra tarsal simples, com dente basal subquadrado com bordas arredondadas (Fig. 9). Abdome com seis segmentos visíveis. Primeiro esterno com linha pós-coxal arredondada, incompleta, dirigindo-se para a borda lateral (Fig. 10).

Genitália do macho. Delgada a robusta. Lobo médio, na maioria das espécies, com a parte basal mais larga, estreitando-se em direção ao ápice, este arredondado ou truncado. Parâmeros menores ou de mesmo comprimento que o lobo médio e com cerdas longas. Ápice do sifăo com espículas, de forma e tamanho diferentes; região pré-apical com ou sem ampola. Cápsula sifonal achatada.

Genitália da fêmea. Espermateca em forma de "C", simples, composta de uma série de anéis imbricados. Ramo, nódulo e ducto com tamanho variável. Infundíbulo, bem esclerotinizado, cônico ou cilíndrico, com tamanho variável. Coxitos, cada um, com estilo e cerdas fortes.

Discussão taxonômica. Segundo VANDENBERG \& GORDON (1988), Neocalvia e Erythroneda são grupos irmãos, pois apresentam um ancestral comum. A hipótese de monofilia para o grupo é baseada no compartilhamento de caracteres derivados, tais como: a coloração do élitro marrom avermelhado a amarelado, superfície ventral laranja acastanhada, antena alongada e olhos grossamente facetados.

Como caracteres derivados, Erythroneda apresenta: epipleura elitral bifoveada para a recepção dos fêmures, parâmeros da genitália masculina contíguos na base e sifão com ampola subapical livre. Em Neocalvia, a epipleura é plana, larga e não apresenta escavações para a recepção dos fêmures e os parâmeros da genitália do macho são afastados, não contíguos. Quanto à ampola pré-apical do sifão, que 
os autores citam como caráter autapomórfico para o gênero Erythroneda, aparece de forma evidente em $N$. anastomozans, $N$. dentatofasciata e $N$. blanchardi. Nas demais espécies, a ampola pré-apical não aparece como estrutura livre e evidente, porém em $N$. cayennensis e $N$. guerinii, nessa região do sifão, ocorre um enrugamento da parede externa, sem a definição da ampola. Em $N$. mniszechii e $N$. fulgurata, o sifão é completamente desprovido de tal estrutura.

\section{Chave para identificação das espécies de Neocalvia (exceto $N$. guerinii e N. areolata)}

1. Tegumento distintamente marrom com máculas amarelas; pronoto com duas máculas laterais, ovaladas e oblíquas (Fig. 16). GUATEMALA, PANAMÁ, Guiana Francesa, Colômbia, Brasil (AM, PA, RN, PB, PE) . . . . . . .

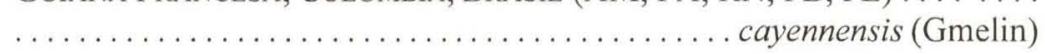

- Tegumento distintamente amarelo com máculas marrons; pronoto não como

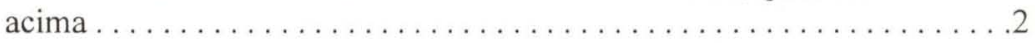

2. Mácula justa sutural livre, em faixa, acompanha toda a extensão do élitro . . . 3 - Mácula justa sutural unida às demais máculas . ................. 4

3. Primeira mácula, grande, em forma de vírgula; mácula do disco central em forma de "U" (Fig. 24). Guiana Francesa, Brasil (BA, MG, ES, RJ, SP, PR, $\mathrm{SC}, \mathrm{RS}) \ldots \ldots \ldots \ldots \ldots \ldots \ldots \ldots \ldots \ldots \ldots \ldots \ldots \ldots \ldots \ldots \ldots \ldots$ fulgurata (Mulsant)

- Primeira mácula unida à terceira, formando, no disco central, um "L" no élitro direito (Fig. 11). Guiana FrancESA, BRASIL (MG, RJ, SP, PR, SC, RS) . . anastomozans Crotch

4. Cada élitro com uma grande mácula arredondada basal; distintas faixas transver-

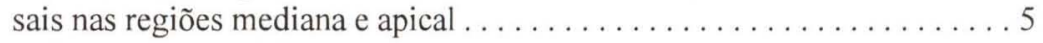

- Cada élitro com muitas máculas irregulares unidas, restando apenas poucas áreas amarelas expostas do tegumento (Fig. 29). VenEZUELA, PARAGUAI, ARGENTINA, URUGUAI . . . . . . . . . . . . . . . dentatofasciata Burmeister

5. Faixa transversal mediana trissinuosa nas suas bordas anteriores e posteriores; duas máculas apicais, a interna unida à justa sutural, formando um arco espesso (Fig. 20). Peru, BolíviA .............. blanchardi (Mulsant)

- Faixa transversal mediana não sinuosa, mácula apical triangular unida à justa sutural (Fig. 36) GUIANA, SurinAmE, EQUAdOR, Brasil (MA, GO) .... . mniszechii Crotch

\section{Neocalvia anastomozans Crotch, 1874}

Figs 1-15

Neocalvia anastomozans Crotch, 1871: 4 (lista); 1874: 130 (descrição). - Weise, 1904a: 195 (citação). - Korschefsky, 1932: 530 (catálogo). - Camargo, 1937: 364-372 (sistemática, biologia, chave, sinonimia). - Blackwelder, 1945: 454 (catálogo). - Marinoni \& Almeida, 1983: 268-270,273 (morfologia). - Arioli, 1985: 27-29 (chave). - Gordon, 1987: 15 (catálogo).

Halysia anastomozans: Gemminger \& Harold, 1876: 3756 (catálogo).

Psyllobora grandis Costa Lima, 1937: 12 (descrição).

Revta bras. Zool. 15 (1): 167 - 189, 1998 
Diagnose. Corpo arredondado, tegumento amarelo, máculas e escutelo marrons. Pronoto com três máculas, uma apical e duas basais, ligadas entre si pelas suas bordas internas. Cada élitro com sete máculas: a primeira alongada, com aproximadamente metade do comprimento e paralela à sutura; segunda retangular, com comprimento menor que a primeira e paralela a essa; terceira triangular, estreita, alongada, com base afilada, sobre o calo umeral, mais estreita que as anteriores e paralela às mesmas; quarta quadrangular, abaixo da segunda e unida à primeira pelo sua borda interna formando um "L" (no élitro direito); quinta alongada, na mesma linha da terceira e ao lado da quarta; sexta triangular, apical, robusta, paralela à sutura e à união da primeira e quarta máculas; sétima triangular, estreita, alongada, com o ápice afilado voltado para o ápice do élitro, margeando a borda lateral. Mácula justa sutural presente, livre, acompanhando toda a sua extensão (Fig. 11).

Genitália do macho. Delgada; lobo médio largo na base, estreitando, gradativamente, em direção ao ápice, esse truncado; parâmeros mais curtos que o lobo médio, com a mesma largura do ápice à base e com pêlos longos (Figs 12, 13); ápice do sifão com quatro espículas na bolsa prepucial, duas longas e grossas e duas curtas e finas, sendo essas duas últimas a metade do comprimento das anteriores; região pré-apical do sifão com ampola (Fig. 14).

Gentitália da fêmea. Espermateca em forma de "C" fechado, com ápice arredondado; ramo proeminente, de tamanho subigual ao nódulo; ducto igual à metade do infundíbulo; este cilíndrico, três vezes mais longo que largo e com região anterior dilatada (Fig. 15).

Medidas. Comprimento de 5,00 a 6,58 mm e largura de 4,25 a 5,83 mm.

Discussão taxonômica. Neocalvia anastomozans assemelha-se a $N$. fulgura$t a$, principalmente pelo padrão das máculas elitrais, mais alongado. Ambas apresentam mácula justa sutural livre, tomando todo o comprimento do élitro; máculas da borda lateral estreitas e alongadas e mácula apical em triângulo robusto. Além disso, as máculas do pronoto possuem o mesmo padrão. Diferem pelas máculas do disco central, que em $N$. anastomozans é em forma de "L", no élitro direito, e em $N$. fulgurata é em forma de "U". N. anastomozans apresenta lobo médio mais afilado, com ápice truncado e sifão com ampola evidente e espículas de comprimento e espessura diferentes entre si.

Material-tipo. O lectótipo foi estudado e está depositado no Department of Zoology, University of Cambrigde, Cambridge, Inglaterra.

Material examinado. BRASIL: (?), ex Col. J. Weise, um exemplar (ZMHU); Minas Gerais: Passa Quatro, VII.1982, M. Alvarenga leg., três exemplares (DZUP); sem data, J. Melzer leg., um exemplar (MZSP); Pouso Alegre, IX.1962, F.S. Pereira leg., um exemplar (MZSP); Rio de Janeiro: Itatiaia, 18.IV.1931, J.F. Zikán leg., um exemplar (MNRJ); 16.V.1932, J.F. Zikán leg., um exemplar (MNRJ); 01.III.1933, J.F. Zikán leg., um exemplar (MNRJ); 24.VIII.1934, J.F. Zikán leg., um exemplar (MNRJ); 04.III.1935, J.F. Zikán leg., um exemplar (MNRJ); São Paulo: (?), sem data, sem coletor, dois exemplares (BMNH); Barueri, XII.1959, K. Lenko leg., um exemplar (MZSP); 23.VII.1960, K. Lenko leg., um exemplar (MZSP); 25.II.1961, K. Lenko leg., um exemplar (MZSP); 09.IV.1961, K. Lenko leg., um exemplar (MZSP); X.1965, K. Lenko leg., um exemplar (MZSP); XII.1965, K. Lenko leg., 


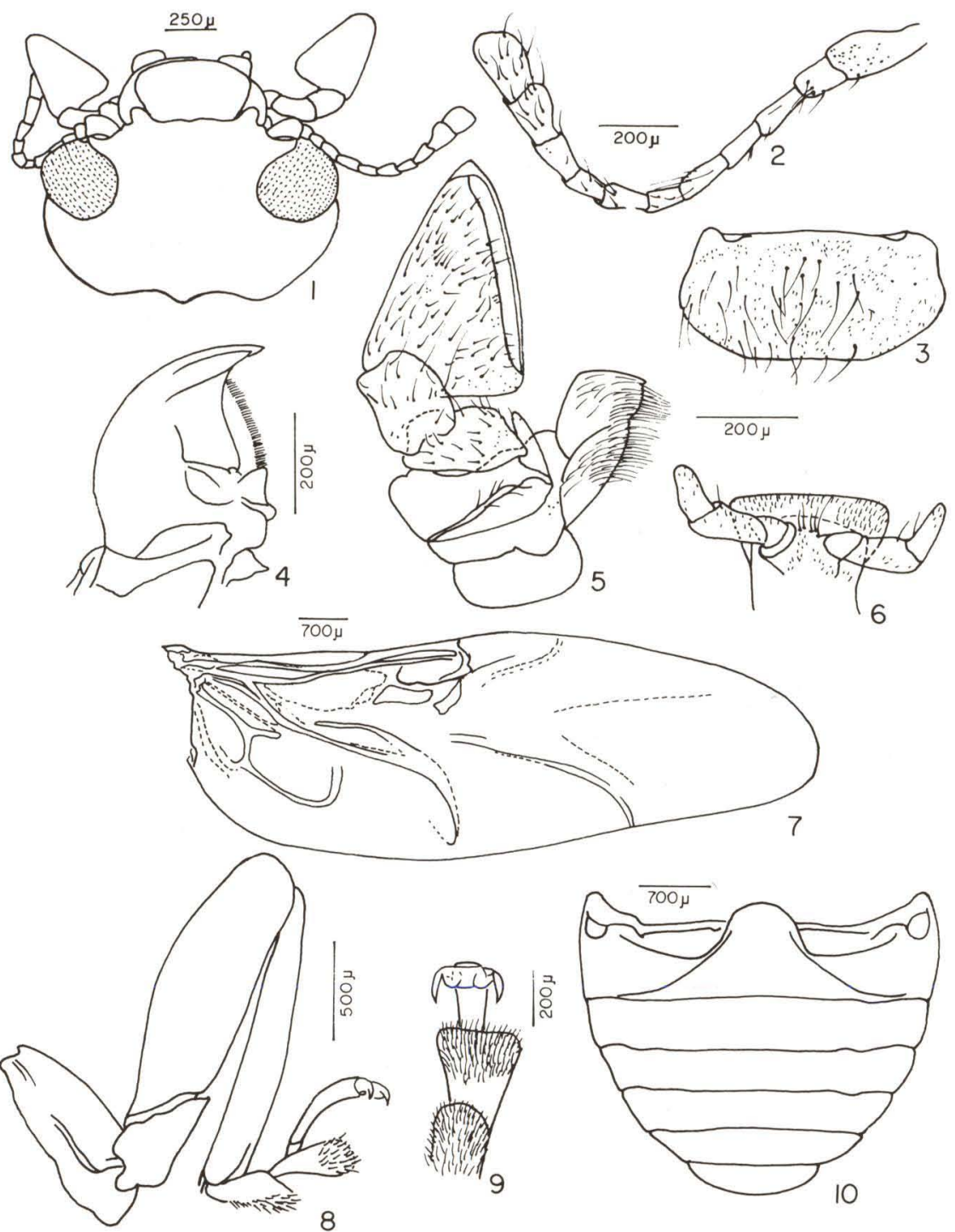

Figs 1-10. Neocalvia anastomozans. (1) Cabeça, vista dorsal; (2) antena; (3) labro; (4) mandibula; (5) maxila; (6) lábio; (7) asa membranosa; (8) perna metatorácica; (9) garra tarsal; (10) abdome, vista ventral.

dois exemplares (MZSP); 08.X.1966, K. Lenko leg., dois exemplar (MZSP); Campinas, sem data, F.C. Camargo leg., um exemplar (DZUP); sem data, sem coletor, dois exemplares (DZUC); Batêa, 02.XI.1940, F. Lane leg., um exemplar (MNRJ); Guarulhos (Sítio Bananal), 15.X.1936, J. Halik leg., um exemplar (DZUP); Sorocaba, sem data, sem coletor, três exemplares (DZUC); Paraná: Curitiba, 02.II.1996, Pierangeli leg., um exemplar (DZUP); Jundiaí do Sul, 

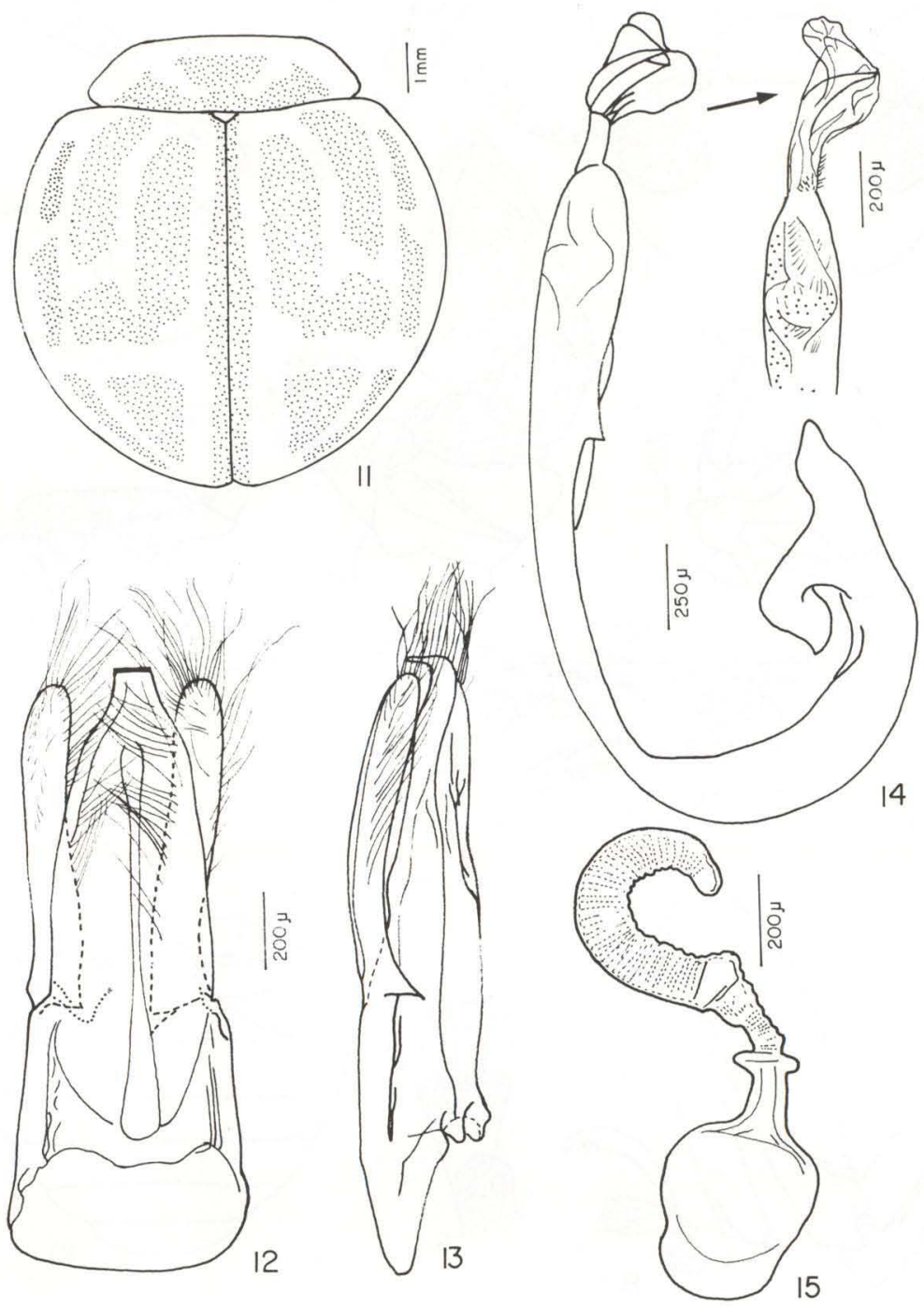

Figs 11-15. Neocalvia anastomozans. (11) Pronoto e élitros, vista dorsal; tégmen (12) vista ventral; (13) vista lateral; (14) sifão; (15) espermateca.

05.X.1986, PROFAUPAR, um exemplar (DZUP); Ponta Grossa (Vila Velha), IX.1944, Col. F. Justus, dois exemplares (DZUP); Santa Catarina: Chapecó, XI.1962, F. Plaumann leg., um exemplar (MZSP); Seara (Nova Teutônia), 27.IV.1950, F. Plaumann leg., um exemplar (DZUP); 27.IV.19??, F. Plaumann leg., um exemplar (DZUP); IV.1952, F. Plaumann leg., um exemplar (DZUP); VII.1958, 
F. Plaumann leg., um exemplar(DZUP); XI.1958, F. Plaumann leg., três exemplares (DZUP); II.1960, F. Plaumann leg., um exemplar (DZUP); I.1961, F. Plaumann leg., um exemplar (MZSP); X.1962, F. Plaumann leg., dois exemplares (MZSP); II.1966, F. Plaumann leg., dois exemplares (MZSP); X.1970, F. Plaumann leg., um exemplar (MZSP); II.1974, F. Plaumann leg., um exemplar (DZUP); V.1975, F. Plaumann leg., dois exemplares (DZUP); VI.1975, F. Plaumann leg., um exemplar (DZUP); XII.1980, F. Plaumann leg., um exemplar (DZUP); VII.1985, F. Plaumann leg., um exemplar (DZUP); Rio Grande do Sul: Salvador do Sul, 1963, sem coletor, um exemplar (MAPA); 14.X.1966, sem coletor, um exemplar (MAPA). Sem localidade, sem data, O. Monte leg., um exemplar (MNRJ); sem localidade, sem data, sem coletor, quatro exemplares (Lâminas 173/FCC-323, 178/FCC-328, 185/FCC-332, 192/FCC-347) (MNRJ); um exemplar (MNRJ); um exemplar (lectótipo) (DZUC).

\section{Neocalvia cayennensis (Gmelin, 1790)}

Figs 16-19

Coccinella duodecimguttata Fabricius, 1787: 379 (descrição).

Coccinella cayennensis Gmelin, 1790: 1659 (nome novo).

Coccinella connata Olivier, 1791: 71.

Calvia cajennensis [sic]: Mulsant, 1850: 148 (diagnose); 1866-67: 6 (diagnose).

Halyzia cayennensis: Gemminger \& Harold, 1876: 3756 (catálogo).

Neocalvia duodecimguttata: Crotch, 1874: 129 (redescrição, designação espécie-tipo). - Gorham, 1892: 169 (diagnose); Korschefsky, 1932: 530 (catálogo). - Gordon, 1987: 15 (catálogo).

Neocalvia cayennensis: Crotch, 1871: 4 (lista). - Weise, 1904b: 357 (comentário). - Camargo, 1937: 364, 372, 373 (sistemática, biologia, chave). - Blackwelder, 1945: 454 (catálogo).

Diagnose. Corpo arredondado, tegumento e escutelo marrons com máculas amarelas. Pronoto com duas máculas laterais, ovaladas e oblíquas. Cada élitro com sete máculas: primeira ovalada, com base truncada, próxima ao escutelo; segunda em forma de "3" (no élitro direito), rodeando o calo umeral e atingindo, aproximadamente, a metade do élitro, tanto na largura quanto no comprimento; terceira oval, alongada, na mesma linha da primeira e paralela à sutura; quarta arredondada, pouco menor que a primeira, abaixo da segunda; quinta cordiforme, alongada, junto à borda; sexta triangular, com os vértices arredondados, abaixo do espaço entre terceira e quarta máculas, de mesmo tamanho da primeira; sétima alongada, apical, junto à borda. Mácula justa sutural ausente (Fig. 16).

Genitália do macho. Robusta; lobo médio um pouco mais estreito na base, com lados praticamente paralelos e ápice mamilar; parâmeros menores que o lobo médio, com mesma largura da base ao ápice e com pêlos longos (Fig. 17); ápice do sifão com quatro espículas na bolsa prepucial, duas longas, grossas e com ápice afilado e duas muito curtas e finas, com cerca de um quarto do comprimento das anteriores; região pré-apical com parede externa enrugada, mas sem definição da ampola (Fig. 18).

Genitália da fêmea. Espermateca em forma de "C" aberto, com ápice arredondado; ramo proeminente, de tamanho subigual ao nódulo; ducto duas vezes e meia menor que o infundíbulo; este ligeiramente cônico, quatro vezes mais longo que largo (Fig. 19). 

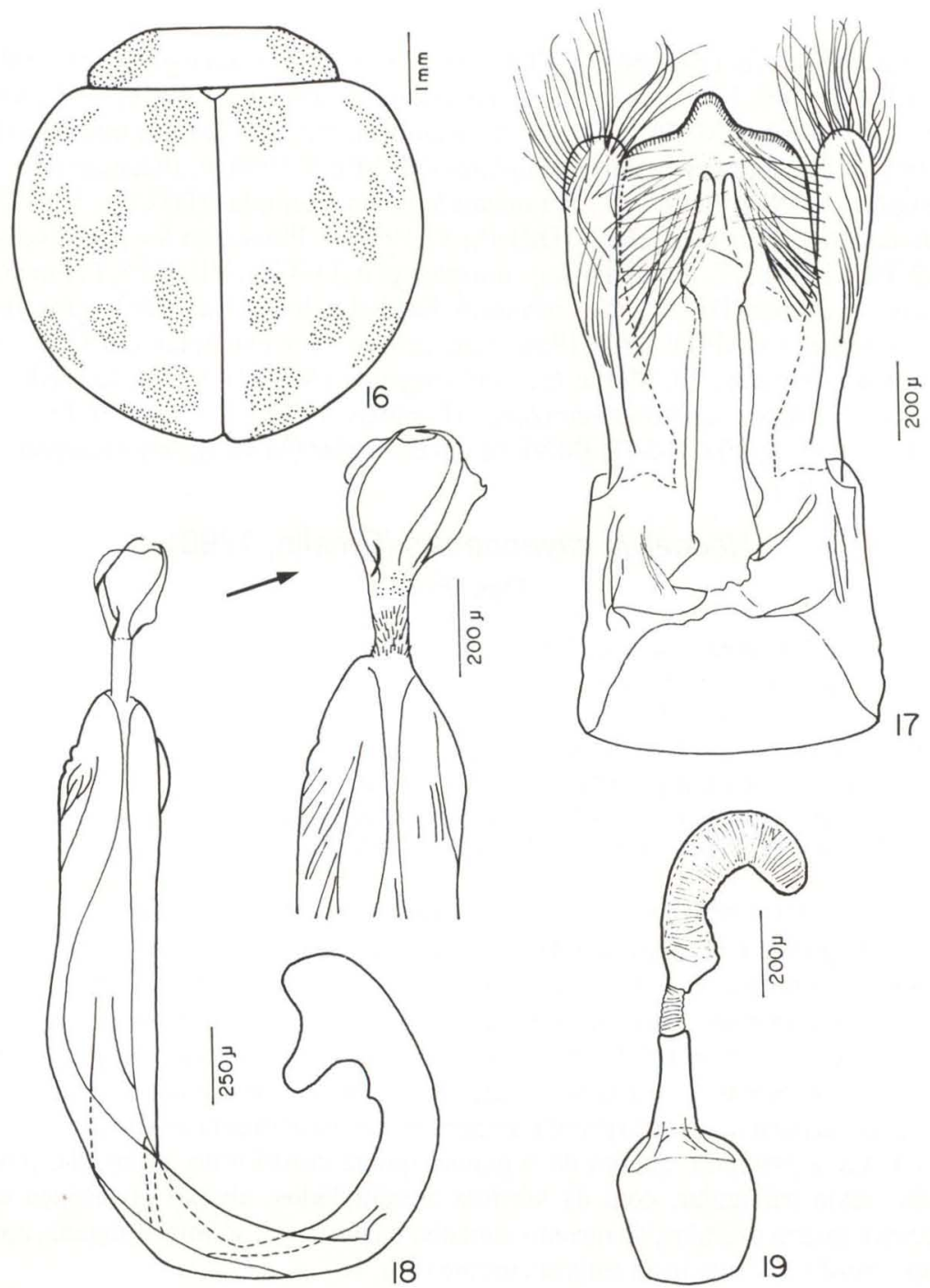

Figs 16-19. Neocalvia cayennensis. (16) Pronoto e élitros, vista dorsal; (17) tégmen, vista ventral; (18) sifão; (19) espermateca.

Medidas. Comprimento de 5,50 a 6,00 mm e largura de 4,42 a 5,42 mm.

Variação intraespecífica. Segunda mácula pode estar com as projeções, basal e mediana, fusionadas, lembrando um "9" (no élitro direito).

Discussão taxonômica. Neocalvia cayennensis difere de todas as demais espécies pela coloração e pelo padrão elitral que apresenta máculas menores, deixando uma área livre no disco central; pela ausência da mácula justa sutural; pelo pronoto com duas máculas laterais, ovaladas e oblíquas. Aproxima-se de N. blan- 
chardi pelo lobo médio robusto, de lados paralelos e ápice mamilar, sendo que em $N$. cayennensis o ápice é mais projetado e afilado do que em $N$. blanchardi. Difere por apresentar duas das quatro espículas da bolsa prepucial, muito afiladas e com cerca de um quarto do comprimento das outras duas.

Material-tipo. Segundo GORDON (1987), o material-tipo está em local desconhecido.

Material examinado. Guatemala, Baja Vera Paz: San Jeronimo (São Gerônimo), sem data, Col. Champion, dois exemplares (BMNH). PANAMÁ: Cerro Campana, 01.VIII.1970, Stockwell leg., um exemplar (BMNH). ColômBIA: (?), sem data, sem coletor, três exemplares (ZMHU). BrASIL, Amazonas: Parintins, I.1940, Col. Balint, um exemplar (Lâmina 967/FCC-1369) (MNRJ); Pará: Fordlândia, 13.I.1946, F.C. Camargo leg., um exemplar (MNRJ); Rio Grande do Norte: Natal, V.1950, Col. M. Alvarenga, um exemplar (DZUP); Paraíba: João Pessoa, VII.1995, Pereira leg., um exemplar (DZUP); Pernambuco: (?), sem data, Fry leg., um exemplar (BMNH); Bonito, II. 1983, A. Koebele leg., um exemplar (Lâmina 494/FCC-604) (MNRJ); Bahia: (?), sem data, Bondar leg., um exemplar (DZUP); sem data, Bondar leg., um exemplar (BMNH); sem data, Reed leg., um exemplar $(\mathrm{BMNH})$. Sem localidade, sem data, sem coletor, dois exemplares (Lâminas 187/FCC-165b e 493/FCC-630) (MNRJ); um exemplar (BMNH).

\section{Neocalvia blanchardi (Mulsant, 1850)}

Figs 20-23

Calvia blanchardi Mulsant, 1850: 147 (descrição); 1866-67: 6 (diagnose).

Neocalvia blanchardi: Crotch, 1871: 4 (lista); 1874: 130 (citação). - Korschefsky, 1932: 530 (catálogo). - Blackwelder, 1945: 454 (catálogo).

Halyzia blanchardi: Gemminger \& Harold, 1876: 3756 (catálogo).

Diagnose. Corpo arredondado, tegumento amarelo pálido, máculas e escutelo marrom claros. Pronoto com uma mácula trapezoidal marrom clara contendo, na metade do seu comprimento, duas entradas em forma de triângulo. Essa mácula estende-se da região anterior, onde é tão larga como o espaço inter-orbital, até a posterior, onde ocupa a metade da largura do pronoto. Cada élitro com cinco máculas: primeira arredondada, interna, grande, situada no primeiro terço, fusionada à segunda por três quintos do seu lado externo; segunda alongada e afilada, sobre o calo umeral; terceira trissinuosa nas suas bordas anteriores e posteriores, com, aproximadamente, a mesma largura em toda extensão, unida à justa sutural e paralela à borda lateral, mais perto dessa do que a segunda mácula; quarta apical, em forma de arco espesso, ligada à justa sutural pelo seu lado interno; quinta alongada, paralela à borda lateral e ligada à quarta pela terça parte do seu lado interno. Mácula justa sutural presente, acompanhando toda a sua extensão (Fig. 20).

Genitália do macho. Robusta; lobo médio quadrangular, muito largo, pouco estrangulado na base, com ápice mamilar; parâmeros pouco mais curtos que o lobo médio, clavados no ápice e com pêlos longos (Fig. 21); ápice do sifão com quatro espículas robustas na bolsa prepucial, sendo as duas menores com cerca de um terço do comprimento das outras duas; região pré-apical do sifão com ampola sanfonada (Fig. 22). 

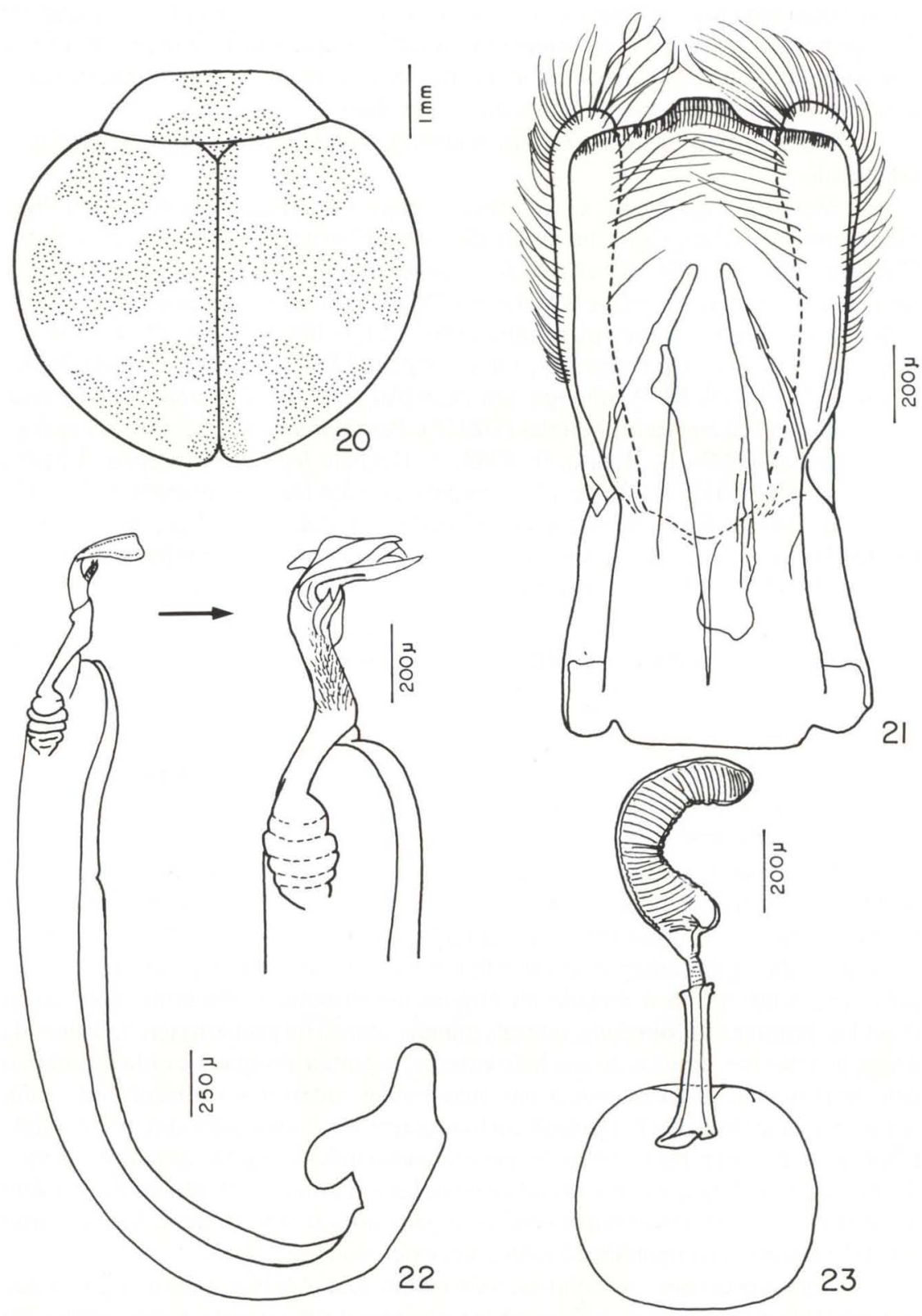

Figs 20-23. Neocalvia blanchardi. (20) Pronoto e élitros, vista dorsal; (21) tégmen, vista ventral; (22) sifão; (23) espermateca. 
Genitália da fêmea. Espermateca em forma de "C" semi-aberto, com ápice redondo; ramo proeminente, de tamanho igual ao nódulo; ducto com aproximadamente um quinto do comprimento do infundíbulo; este ligeiramente cônico, seis vezes mais longo que largo (Fig. 23).

Medidas. 6,25 $\mathrm{mm}$ de comprimento e 5,75 $\mathrm{mm}$ de largura.

Discussão taxonômica. Esta espécie assemelha-se a $N$. dentatofasciata pelo padrão das máculas elitrais, com uma grande faixa transversal mediana e pelas máculas sobre o calo umeral. Diferencia-se pela faixa transversal que, em $N$. blanchardi, apresenta-se, aproximadamente, da mesma largura em toda extensão, enquanto que, em $N$. dentatofasciata, essa mácula é cerca de três vezes mais larga na região da sutura. Outra diferença está na mácula apical, em forma de arco espesso, ligada à justa sutural, ausente em $N$. dentatofasciata. A genitália do macho em $N$. blanchardi difere de todas as demais espécies, por apresentar o lobo médio quadrangular, muito largo e com ápice mamilar; além disso a ampola é sanfonada.

Material-tipo. O holótipo não foi examinado e, segundo MULSANT (1850), está depositado no Muséum National d'Histoire Naturelle, Paris, França, porém não foi localizado.

Material examinado. Peru, Cuzco: Cuzco (Huadquina), 31.VII.1911, Yale Peruvian Exp., um exemplar (Lâmina 472/FCC-582) (MNRJ); 30.VII.1911, Yale Peruvian Exp., um exemplar (Lâmina 473/FCC-583) (MNRJ); Charcho, sem coletor, um exemplar (BMNH). BolíviA, La Paz: Chulumani, 27.X.1983, Mielke \& Casagrande leg., um exemplar (DZUP).

\section{Neocalvia fulgurata (Mulsant, 1850)}

Figs 24-28

Calvia fulgurata Mulsant, 1850: 150 (descrição), 1866-67: 7 (diagnose).

Neocalvia fulgurata: Crotch, 1871: 4 (lista), 1874: 129 (redescrição). - Korschefsky, 1932: 530 (catálogo). - Camargo, 1937: 364, 373, 374 (sistemática, biologia, chave). - Blackwelder, 1945: 454 (catálogo). - Arioli, 1985: 27-29 (chave). - Gordon, 1987: 15 (catálogo).

Halysia fulgurata: Gemminger \& Harold, 1876: 3758 (catálogo).

Diagnose. Corpo arredondado, tegumento amarelado, máculas e escutelo marrons. Pronoto com três máculas, uma apical e duas basais ligadas entre si pelas suas bordas internas. Cada élitro com sete máculas: a primeira grande, mais interna, em forma de vírgula, com a ponta angulosa voltada para o ápice do élitro; segunda alongada, cerca de duas vezes e meia o comprimento da primeira, sobre o calo umeral e paralela à borda; terceira e quarta unidas pelo ápice, em forma de "U", situadas no disco central, envolvendo o ápice da primeira; quinta alongada, abaixo da segunda e com comprimento pouco menor que o da terceira; sexta triangular, apical, com a base acompanhando o ápice da mácula em forma de "U"; sétima alongada, estreita, na mesma linha da quarta, com ápice afilado voltado para o ápice do élitro. Mácula justa sutural presente, livre, acompanhando toda a sua extensão (Fig. 24).

Genitália do macho. Semi-robusta; lobo médio largo na base, com um afilamento em direção ao ápice, este arredondado; parâmeros de mesmo compri- 

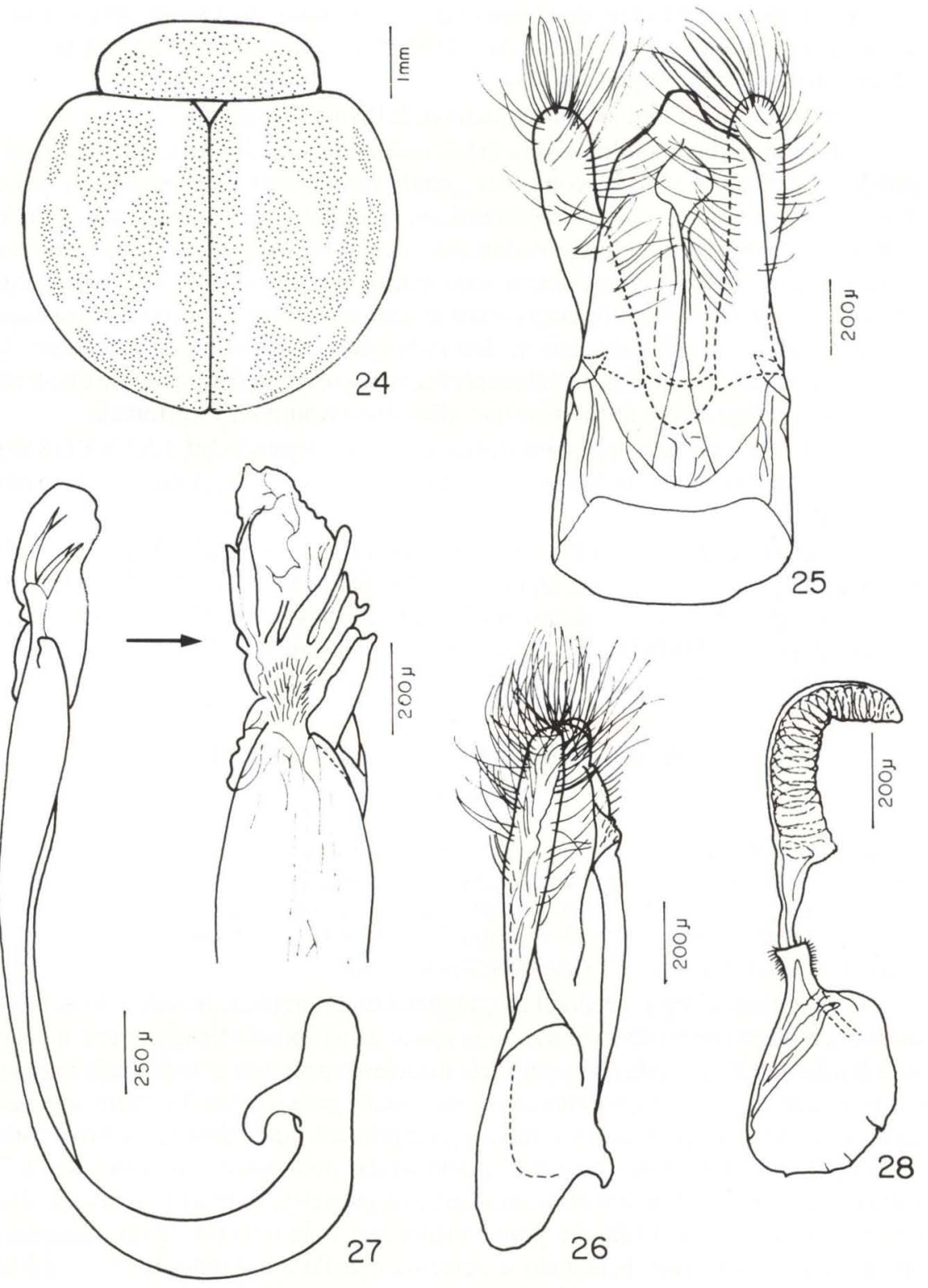

Figs 24-28. Neocalvia fulgurata. (24) Pronoto e élitros, vista dorsal; tégmen (25) vista ventral; (26) vista lateral; (27) sifão; (28) espermateca. 
mento do lobo médio, com mesma largura da base ao ápice e com pêlos longos (Figs $25,26)$; ápice do sifão com quatro espículas afiladas na bolsa prepucial, duas menores com cerca de três quartos do comprimento das outras duas (Fig. 27).

Genitália da fêmea. Espermateca em forma de "C" aberto, com ápice ligeiramente afilado; ramo proeminente, com tamanho correspondente a dois terços do nódulo; ducto duas vezes menor que o infundíbulo; este cilíndrico, duas vezes mais longo que largo e com região anterior pouco dilatada (Fig. 28).

Medidas. Comprimento de 4,50 a 6,08 $\mathrm{mm}$ e largura de 4,08 a 6,00 mm.

Variação intraespecífica. No pronoto, as regiões anteriores das máculas apical e basais podem estar fusionadas, formando duas gotas dentro de uma grande mácula.

Discussão taxônomica. $N$. fulgurata assemelha-se de $N$. anastomozans pelo padrão de máculas do pronoto e dos élitros. Difere pela forma do lobo médio, mais largo e com ápice mamilar, arredondado; pela ausência da ampola na região pré-apical do sifão e pelo tamanho e espessura das espículas.

Material-tipo. O lectótipo, designado por GoRDON (1987), foi examinado e está depositado no Department of Zoology, University of Cambridge, Cambridge, Inglaterra e os paralectótipos, no The Natural History Museum, Londres, Inglaterra.

Material examinado. BRASIL: (?), sem data, sem coletor, dois exemplares (ZMHU); Bahia: (?), sem data, Col. Fry, dois exemplares (BMNH); Água Preta, 12.X.1945, P. Silva leg., um exemplar (ZMHU); Minas Gerais: São João del Rei, sem data, sem coletor, um exemplar (ZMHU); Monte Verde, 18.XI.1966, J. Halik leg., um exemplar (MZSP); 10.IV.1967, J. Halik leg., um exemplar (MZSP); 06.II.1970, J. Halik leg., um exemplar (MZSP); Espirito Santo: Santa Tereza, 12.X.1928, O. Conde leg., um exemplar (ZMHU); Rio de Janeiro: (?), sem data, Col. Fry, dois exemplares (BMNH); Itatiaia, 01.V.1933, J. F. Zikan leg., um exemplar (DZUP); Alto da Serra, 05.II.1940, S. Moreira leg., um exemplar (DZUP); São Paulo: São Paulo (Jabaquara), I.1939, Col. Diringshofen, um exemplar (MNRJ); Campinas, sem data, sem coletor, um exemplar (DZUP); São Roque, 21.II.1937, sem coletor, um exemplar (Lâmina 108/FCC-245) (MNRJ); Paraná: Curitiba, Col. Claretiano, X.1989, um exemplar (MCIC); Castro, 20.VIII.1983, A. Lara leg., um exemplar (MCIC); Carambei, X.1944, A. Col. F. Justus Jr., dois exemplares (DZUP); Telêmaco Borba, 07.X.1986, PROFAUPAR, um exemplar (DZUP); Santa Catarina: Blumenau, VI.1957, Col. Diringshofen, um exemplar (DZUP); Chapecó, XI.1962, F. Plaumann leg., um exemplar (MZSP); Mafra, 01.IV.1994, D. T. Reynajd leg., um exemplar (DZUP); Seara (Nova Teutônia), 18.XI.1935, F. Plaumann leg., um exemplar (DZUP); XI.1943, F. Plaumann leg., um exemplar (DZUP); VII.1959, F. Plaumann leg., um exemplar (DZUP); X.1962, F. Plaumann leg., um exemplar (MZSP); IX.1967, F. Plaumann leg., dois exemplares (DZUP); Timbó, VI.1954, Col. Diringshofen, um exemplar (DZUP); III.1956, Col. Diringshofen, dois exemplares (DZUP); X.1958, Col. Diringshofen, dois exemplares (DZUP). Sem localidade, sem data, sem coletor, dois exemplares (Lâminas 109/FCC-246 e 108/FCC-245) (MNRJ); um exemplar (Lectótipo) (DZUC); um exemplar (MZSP); um exemplar (Paralectótipo) (BMNH); dois exemplares (DZUP). "Amer. m", sem data, sem coletor, 1 exemplar (ZMNH). 


\section{Neocalvia dentatofasciata (Burmeister, 1874)}

Figs 29-33

Calvia dentatofasciata Burmeister, in Berg, 1874: 289 (descrição).

Halysia dentatofasciata: Gemminger \& Harold, 1876: 3757 (catálogo).

Neocalvia bruchi Weise, 1904a: 194 (descrição). - Korschefsky, 1932: 530 (catálogo).

Neocalvia dentatofasciata: Bruch, 1915:387 (catálogo, sinonimia). - Korschefsky, 1932: 530 (catálogo).

- Camargo, 1937: 364, 375, 376 (sistemática, biologia, chave). - Blackwelder, 1945: 454 (catálogo).

Diagnose. Corpo arredondado, tegumento amarelado, máculas e escutelo marrom escuras. Pronoto com três máculas, uma apical e duas basais, ligadas entre si pelas suas bordas internas. Cada élitro com muitas máculas irregulares, unidas, formando duas faixas nos dois terços basais: a primeira da sutura até a região pós-umeral e a segunda completa, da sutura até a margem lateral. O terço apical com uma mácula triangular unida à sutura e ao ápice elitral e outra afilada na margem lateral. Restam em cada élitro, três áreas expostas do tegumento amarelo: uma arredondada na base; uma de contorno irregular estendendo-se da base até o primeiro terço, inicialmente muito afilada e depois da região umeral mais dilatada, até a região central; e uma última amarela em forma de "T" com bordas irregulares com haste terminando no ápice elitral e a base estendendo-se desde a metade até a margem lateral (Fig. 29).

Genitália do macho. Robusta; lobo médio largo na base, estreitando gradativamente, até o primeiro terço, onde apresenta uma constrição, continuando a estreitar em direção ao ápice, este truncado; parâmeros largos, de comprimento subigual ao lobo médio, com mesma largura da base ao ápice e com pêlos longos (Figs 30 e 31); sifão com borda externa denteada e ápice com quatro espículas na bolsa prepucial, duas longas e grossas e duas curtas e finas, sendo as últimas um pouco menos que a metade do comprimento das anteriores; região pré-apical do sifão com ampola (Fig. 32).

Genitália da fêmea. Espermateca em forma de "C" fechado, com ápice redondo; ramo pouco proeminente, de tamanho igual ao nódulo; ducto de tamanho subigual ao infundíbulo; este cilíndrico, duas vezes mais longo que largo (Fig. 33).

Medidas. Comprimento de 5,17 a 6,00 $\mathrm{mm}$ e largura de 4,17 a 4,92 $\mathrm{mm}$.

Variação intraespecífica. A primeira faixa elitral pode estar dividida em três máculas: a primeira unida à faixa mediana; a segunda ovalar e a terceira, menor, sobre o calo umeral. As faixas elitrais podem estar desligadas da linha sutural. A mácula do terço apical pode apresentar-se ovalada.

Discussão taxonômica. $N$. dentatofasciata é espécie afim de $N$. blanchardi, diferindo principalmente pelo padrão de máculas grandes, ocupando quase toda a extensão do élitro. Além disso, a genitália de $N$. dentatofasciata apresenta lobo médio distinto daquela espécie. Aproxima-se de $N$. mniszechii pela forma do lobo médio, com estrangulamento. Difere por apresentar o contorno do lobo médio não anguloso e a ampola evidente no sifão.

Material-tipo. O holótipo de Neocalvia bruchi Weise, 1904, um sinômimo de $N$. dentatofasciata (Burmeister, 1874), de San Miguel de Tucumán, Argentina, foi estudado e está depositado no Zoologisches Museum der Humboldt Universitaet, Berlim, Alemanha. 


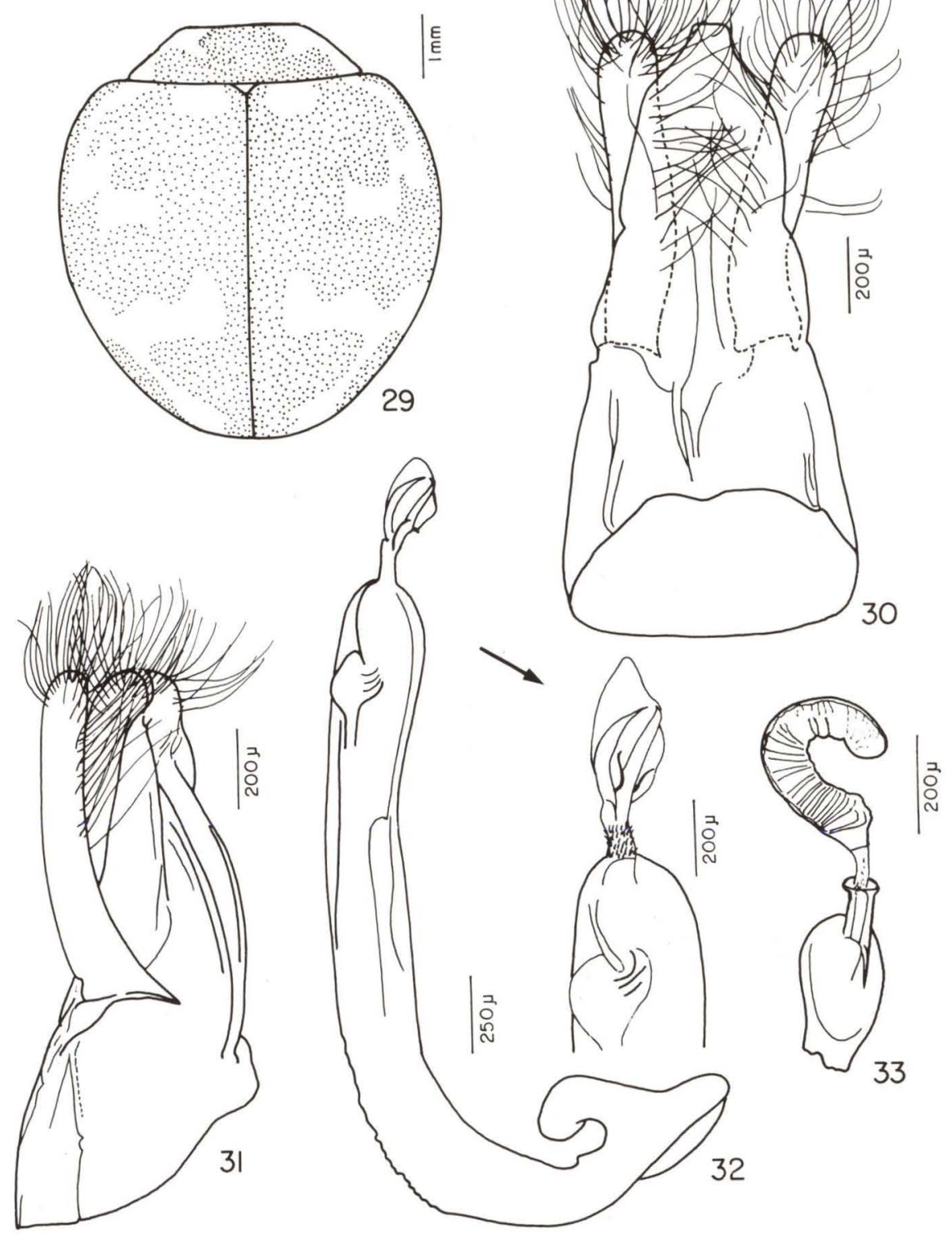

Figs 29-33. Neocalvia dentatofasciata. (29) Pronoto e élitros, vista dorsal; tégmen (30) vista ventral; (31) vista lateral; (32) sifão; (33) espermateca. 
Material examinado. Venezuela, (D.F.) Caracas: Prado de Maria, 29.I.1980, G.S. Fernandez leg., um exemplar (BMNH). PARAGUAI: (?), 1930, Col. Sicard, um exemplar (DZUP); (?), sem data, sem coletor, um exemplar (Lâmina 102/FCC-240) (MNRJ). ARgentinA, Buenos Aires: Buenos Aires, M.J. Viana leg., um exemplar (DZUP); 07.XI.1919, H.E. Box leg., quatro exemplares (BMNH); Chaco: Vilela, 24.V.1936, um exemplar (Lâmina 103/FCC-241) (MNRJ); Tucumán: San Miguel de Tucumán, sem data, sem coletor, um exemplar (ZMHU); sem data, sem coletor, um exemplar (DZUC). URUGUAI, Montevideo: Sayago, II.1969, E.M. Casella leg., um exemplar (BMNH). Sem localidade, sem data, sem coletor, um exemplar (Lâmina 58/FCC-60) (MNRJ).

\section{Neocalvia guerinii Crotch, 1874}

Figs 34-35

Neocalvia guerinii Crotch, 1874: 130 (descrição). - Korschefsky, 1932: 530 (catálogo). - Blackwelder, 1945: 454 (catálogo). - Gordon, 1987: 15 (catálogo).

O único exemplar obtido, desta espécie, para estudo foi o holótipo. Como este não se encontrava em bom estado, foi impossível fazer o desenho das máculas elitrais. Tentou-se esboçar o padrão elitral, com a descrição original feita por CROTCH (1874), porém a mesma não foi suficiente.

Diagnose de CROTCH (1874): "Very like N. fulgurata, with which it was confounded in Guérin's collection. Thorax similary coloured, elytra with a scutellar common spot, and each with a dental fascia at one-third (not reaching the suture), another at two-thirds (prolonged along the suture to the apex), a third apical, joined by a narrow line to the second."

Corpo arredondado, tegumento amarelado com máculas marrons. Pronoto com três máculas marrons, uma apical e duas basais, ligadas entre si pelas suas bordas internas e tegumento ocre.

Genitália do macho. Delgada; lobo médio com mesma largura até os seus três quartos, quando estreita, gradativamente, em direção ao ápice, este truncado; parâmeros pouco mais curtos que o lobo médio, com mesma largura do ápice a base e com pêlos longos (Fig. 34); região pré-apical do sifão com enrugamento, mas sem definição da ampola (Fig. 35).

Genitália da fêmea. Desconhecida.

Discussão taxonômica. A genitália masculina de $N$. guerinii é muito semelhante à de $N$. anastomozans; o lobo médio possui ápice truncado e comprimento subigual ao dos parâmeros e o sifão apresenta ampola. A única genitália examinada de N. guerinii foi montada, em lâmina, por F.C. Camargo, o que impossibilitou o desenho da vista lateral do lobo médio. O ápice do sifão apresentava-se mal preservado, o que dificultou, a comparação entre as duas espécies. Só um estudo com maior número de exemplares poderá confirmar se esta espécie é válida ou se é sinônima de $N$. anastomozans.

CROTCH (1874) comenta que esta espécie é semelhante a $N$. fulgurata. Provavelmente esta citação esteja incorreta, já que pela descrição as máculas de $N$. guerinii diferem muito daquela espécie. 
Material-tipo. O holótipo, macho, foi examinado e está depositado no Department of Zoology, University of Cambridge, Cambridge, Inglaterra.

Material examinado. BRASIL: tipo, sem data, sem coletor (BMNH).
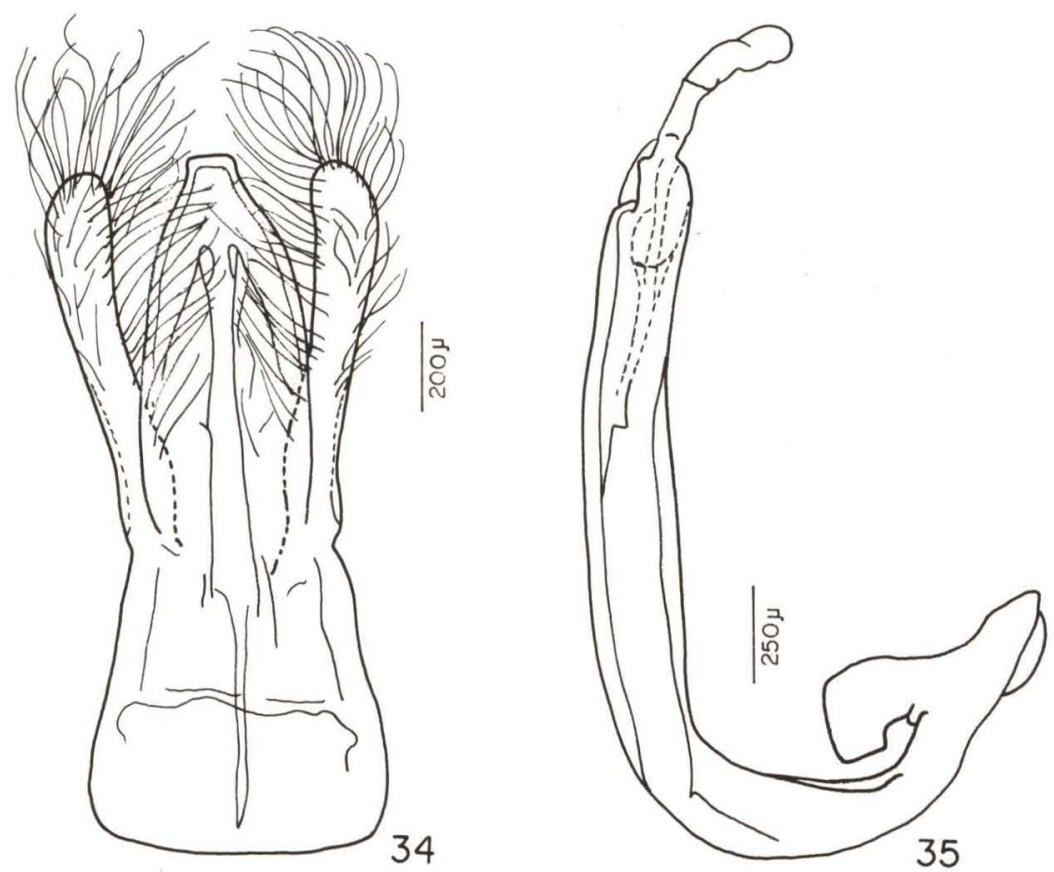

Figs 34-35. Neocalvia guerinii. (34) tégmen, vista ventral; (35) sifão.

\section{Neocalvia mniszechii Crotch, 1874}

Figs 36-39

Neocalvia mniszechii Crotch, 1874: 129 (descrição). - Korschefsky, 1932: 530 (catálogo). Blackwelder, 1945: 454 (catálogo). - Gordon, 1987: 15 (catálogo).

Diagnose. Corpo arredondado, tegumento amarelado, máculas e escutelo marrom avermelhados. Pronoto com uma grande mácula, cuja base compreende três quartos da largura e o ápice, um terço. Regiões laterais da mácula com projeções arredondadas até à metade do comprimento do pronoto. Cada élitro com três máculas: a primeira arredondada, transversal, no terço anterior; a segunda grande, retangular, transversal, em faixa, unida à mácula justa sutural, paralela à borda externa; terceira triangular, no terço posterior, com vértice basal interno fusionado a mácula justa sutural. Mácula justa sutural estendendo-se do ápice à base do élitro (Fig. 36).

Genitália do macho. Robusta; lobo médio largo na base, estreitando, gradativamente, até o meio do mesmo, onde existe uma constrição, depois mantém a mesma largura voltando a estreitar na direção do ápice, este truncado; parâmeros 

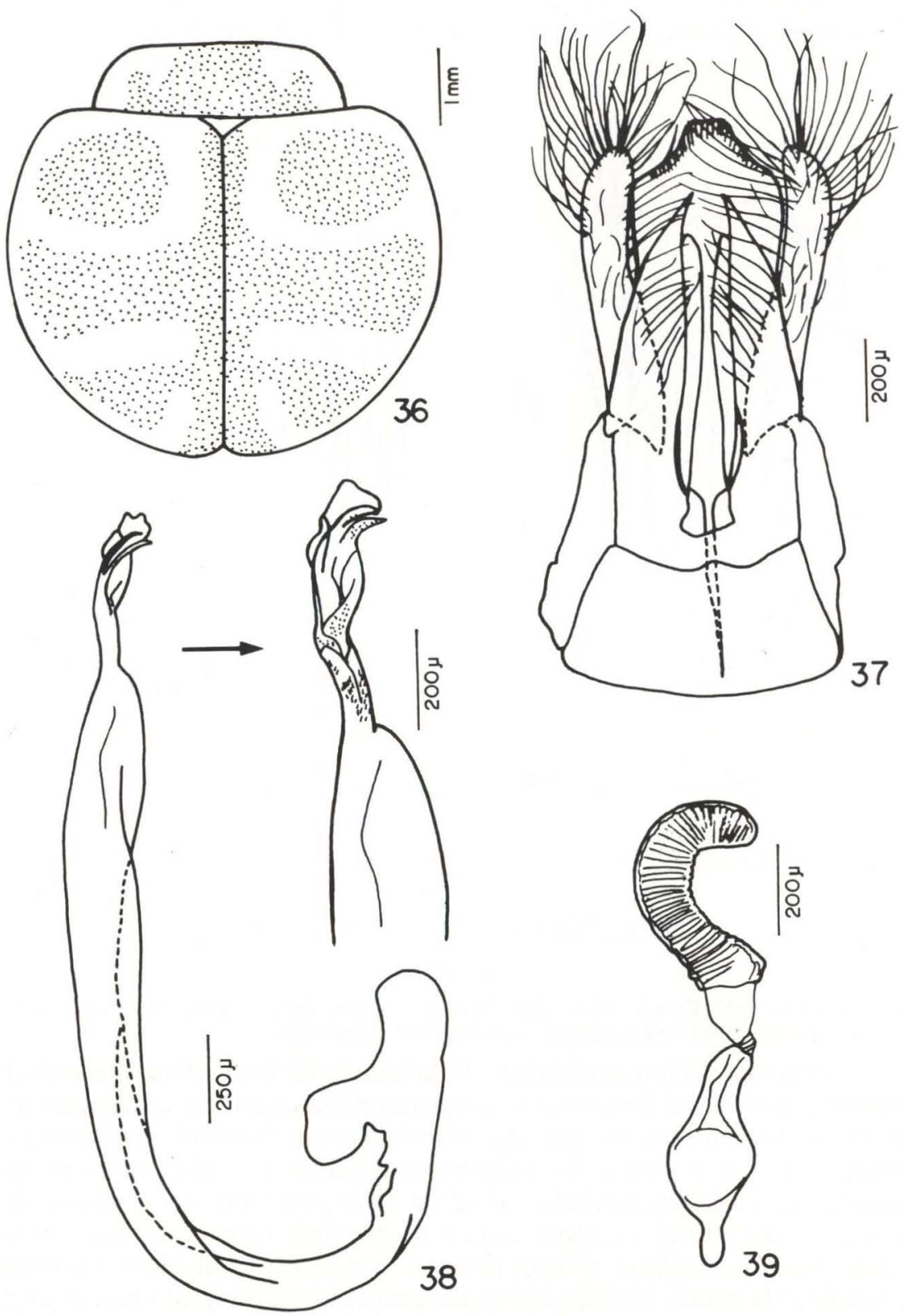

Figs 36-39. Neocalvia mniszechii. (36) Pronoto e élitros, vista dorsal; (37) tégmen, vista ventral; (38) sifão; (39) espermateca. 
menores que o lobo médio, levemente mais largos na base que no ápice e com pêlos longos (Fig. 37); sifão com duas grandes espículas na bolsa prepucial (Fig. 38).

Genitália da fêmea. Espermateca em forma de "C" aberto, com ápice arredondado, ramo proeminente, de tamanho subigual ao nódulo; ducto duas vezes menor que o infundíbulo, este cilíndrico, duas vezes mais longo que largo (Fig. 39).

Medidas. Comprimento de 5,33 a 6,25 mm e largura de 4,75 a 4,83 mm.

Variação intraespecífica. Pronoto com mácula sem projeções laterais e a primeira mácula elitral, arredondada, pode estar unida à segunda, em faixa transversal.

Discussão taxonômica. N. mniszechii difere de todas as demais espécies por apresentar as máculas de coloração marrom avermelhada. Porém, apresenta um padrão de distribuição das máculas semelhante ao de $N$. blanchardi e $N$. dentatofasciata, principalmente no que diz respeito à mácula transversal. Difere por apresentar a primeira mácula arredondada, grande e a mácula transversal com bordas não sinuosas. Difere ainda de $N$. blanchardi, pela forma do lobo médio e pela ausência da ampola no sifão. N. mniszechii apresenta um padrão de lobo médio muito próximo do de $N$. dentatofasciata, sendo as duas únicas espécies a apresentarem um estrangulamento no lobo médio, além da semelhança no ápice. Difere desta, por não apresentar a borda externa do sifão denteado e pela ausência da ampola na região pré-apical do mesmo.

Material-tipo. O holótipo, não foi estudado. GORDON (1987) indica que provavelmente estaria depositado no Múseum National d'Histoire Naturelle, Paris, França, porém não foi localizado.

Material examinado. GuiAnA: Georgetown, 1879, Col. Sharp, 1905-313, um exemplar (BMNH). SURINAME: Paramaribo, 05.1945, E. Stahel leg., três exemplares (BMNH). EQUAdOR, Pichincha: 28.XII.1980, L.I. Ayala leg., um exemplar (PUCE); Los Rios: Quevedo, 25.XII.1978, M.E. Ponte leg., um exemplar (PUCE). BRASIL, Maranhão: São Luis, sem data, Col. J.O. Monteiro, um exemplar (Lâmina 574/FCC-684) (MNRJ); Goiás: Jataí, IX-XI.97, Col. Sicard, um exemplar (Lâmina 890/FCC-1279) (MNHN).

Neocalvia areolata Gorham, 1892

Fig. 40

Neocalvia areolata Gorham, 1892: 169 (descrição). - Korchefsky, 1932: 530 (catálogo). - Camargo, 1937: 376 (comentário). - Blackwelder, 1945: 454 (catálogo).

Como não foi obtido material de Neocalvia areolata, o estudo ficou restrito somente à descrição original e desenho do autor.

Diagnose de Gorham (1892): "Convexa, subhemisphaerica, fere laevis, pallide albo-flavescens, prothorace vitta lata, elytris signature reticulata brunneis, areolas in singulis septem includente, duas basales, duas postmedianas, duas transversas apicales, unam discoidalem subquadratam. 6 millim. Hab. Panamá, Volcan de Chiriqui (Champion). The pattern of the elytra of this species is very elegant. The brown reticulate line is thin, except where it crosses the suture below the basal areae. The ground-colour is pale whitish-yellow, the pattern red-brown. The thoracic 
vitta is narrowly bordered with darker brown, and the entire limb of the thorax and elytra is narrowly brown. In one of the two specimens the apical transverse areolet is united with the large semicircular lateral one; but in the other, wich we figure, the two are quite separate. The two large postmedian areae may be termed "common" to the two elytra."

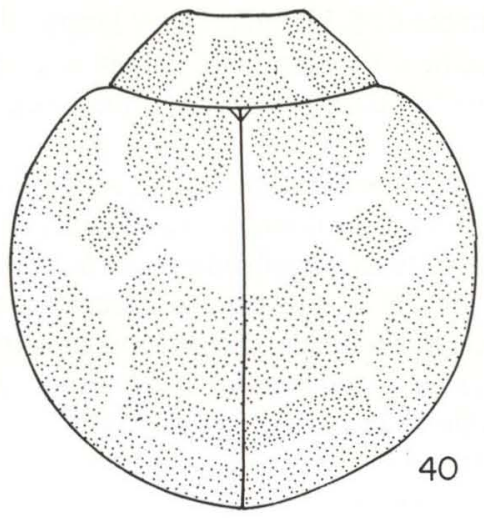

Fig. 40. Neocalvia areolata. Pronoto e élitros, vista dorsal. Cópia ampliada da ilustração de Gorham, 1892.

Material-tipo. Segundo consta na descrição, o material-tipo pertence à Coleção Champion, que se encontra depositada no The Natural History Museum, Londres, Inglaterra, porém não foi localizado pela segunda autora.

Discussão taxonômica. Analisando a morfologia externa da espécie e comparando-a com a das outras espécies do gênero, observou-se que $N$. areolata difere, pelo padrão das máculas do pronoto e dos élitros, pelo pronoto relativamente mais comprido e pelos élitros mais dilatados e arredondados posteriormente. Esta diferença já havia sido observada e comentada por CAMARGO (1937), bem como a colocação duvidosa de $N$. areolata dentro do gênero. Sendo assim, só um estudo minucioso do aparelho genital irá elucidar a real situação desta espécie.

\section{REFERÊNCIAS BIBLIOGRÁFICAS}

ARIOLI, M.C.S. 1985. Coccinellini no Rio Grande do Sul, Brasil (Coleoptera, Coccinellidae). Rev. Centro de Ciências Rurais 15 (1): 5-35.

BERG, F.G.C. 1874. Notícias críticas sobre algunas publicationes entomológicas.

Bol. Acad. Nac. Cienc. Córdova 1: 274-293.

BLACKWELDER, R.E. 1945. Checklist of the Coleopterous Insects of Mexico, Central America, the West Indies, and South America. U.S. States. Nat. Mus. Bull. 185 (3): 343-550.

BRUCH, C. 1915. Catálogo Sistemático de los Coleópteros de la República Argentina. Rev. Mus. La Plata 19 (6): 346-400.

CAMARGo, F.C. 1937. Notas taxonômicas e biológicas sobre alguns coccinelídeos 
do gênero Neocalvia Crotch, predadores de larvas do gênero Psyllobora Chevrolat (Col. Coccinellidae). Rev. Ent. 7 (4): 361-377.

CHAPUIS, F. 1876. Famille des phytophages des érotyliens des endomychides et des coccinellides, 12: 1-424. In: J.T. LACORDAIRE \& F. ChapUIS (Eds). Histoire naturelle des insectes. Genera des Coléoptères.

Crotch, G.R. 1871. List of Coccinellidae. Cambridge, p.1-8. 1874. A Revision of the Coleopterus Family Coccinellidae. London, E.W. Janson, p.1-311.

FABRICIUS, J.C. 1787. Mantissa Insectorum. 2: 1-382.

FÜRSCH, H. 1990. Taxonomy of Coccinellids. Coccinella 2 (1): 7-18.

Gemminger, M \& E. HAROLD. 1876. Catalogus coleopterorum hucusque descriptorum synonymicus et systematicus. Monachii. 12: 3740-3818.

GMELIN, J.F. 1790. Systema Naturae. 1 (4): 1517-2224.

Gordon, R.D. 1985. The Coccinellidae (Coleoptera) of America North of Mexico. Jour. N.Y. Entomol. Soc. 93 (1): 1-912. 1987. A catalogue of the Crotch collection of Coccinellidae (Coleoptera).

Occ. Pap. Syst. Ent. 3: 1-46.

GoRHAM, H.S. 1892. Biologia Centrali-Americana. Insecta, Coleoptera, Coccinellidae. London, Vol. 7, p.150-276.

HAROLD, E. 1875.

Korschefsky, R. 1932. Coleopterum Catalogus. Berlin, W. Junk, Coccinellidae II (120), p.225-659.

LiMA, A.C. 1937. Espécies de Psyllobora (Col. Coccinellidae). Mem. Inst. Oswaldo Cruz 32: 1-12.

MARINONI, R.C. \& L.M. DE ALMEIDA. 1983. Sobre a venação alar em Coccinellidae e Cerambycidae (Coleoptera). Revta bras. Ent. 27 (3/4): 267-275.

Mulsant, E. 1850. Species des Coléoptères Trimères Sécuripalpes. Ann. Sci. Phys. Nat. Lyon. 2 (2): 1-1104. p.1-290.

PODA, J. 1761. Insecta Musei Graecensis que in ordines, genera et species juxta Systema Naturae Linnaei digessit. Graecii, Widmanstad, 12: 1-127.

Olivier, A.G. 1791. Encyclopedie Méthodique - Histoire Naturelle -Insectes, Paris, 6 (1): 1-368.

VANDENBERG, N. \& R.D. Gordon. 1988. The Coccinellidae (Coleoptera) of South America Part I. A revision of the Genus Erythroneda Timberlake, 1943. Revta bras. Ent. 32 (1): 31-43.

Weise, J. 1904a. Coccinellidae in Argentina, Chili et Brasilia. Rev. Mus. La Plata 11: 193-198.

1904b. Synonymische Bemerkungen zu Gorham, Biologia CentraliAmericana: Coccinellidae. Deutsche Ent. Zeitschr. 2: 357-364.

Recebido em 01.III.1997; aceito em 13.IV.1998. 